\title{
Pattern of corneal pathologies in children seen at Yaoundé Gynaeco-Obstetric and Paediatric Hospital, Cameroon
}

This article was published in the following Dove Press journal:

Clinical Ophthalmology

10 October 2013

Number of times this article has been viewed

\author{
Assumpta $L$ Bella ${ }^{1,2}$ \\ Viola A Dohvoma' \\ André O Eballe ${ }^{3}$ \\ Oumarou Abdouramani² \\ 'Faculty of Medicine and Biomedical \\ Sciences, University of Yaoundé I, \\ Yaoundé, ${ }^{2}$ Yaoundé Gynaeco- \\ Obstetric and Paediatric Hospital, \\ Yaoundé, ${ }^{3}$ Faculty of Medicine and \\ Pharmaceutical Sciences, University \\ of Douala, Douala, Cameroon
}

Purpose: To describe the different corneal pathologies and determine the prevalence of corneal blindness amongst children aged $0-15$ years, seen at the ophthalmology unit of a tertiary hospital in Cameroon.

Patients and methods: The medical records of all patients who presented to the Ophthalmic Unit between 2002 and 2010 were reviewed, retrospectively. The records of children aged 0-15 years, presenting with corneal pathologies, were further reviewed. Data collected included age, sex, past medical history, initial visual acuity, type of corneal lesion, and visual acuity at last follow-up.

Results: Of the 7,922 children seen over the study period, 168 had corneal pathologies: a prevalence of $2.1 \%$. Males were more affected than females (male to female ratio: 1.4:1; $P=0.008$ ). The age range was from 2 weeks to 15 years (mean age: 7.1 years; standard deviation: 4.4 years). The leading etiologies were trauma $(48.2 \% ; n=81)$ and infection $(28.0 \% ; n=47)$. Amongst those with available follow-up data, visual impairment and blindness occurred in 50\% of the cases $(\mathrm{n}=12)$, with one case being bilateral.

Conclusion: Trauma is the most frequent cause of corneal blindness in children.

Keywords: keratitis, ocular trauma, childhood blindness

\section{Introduction}

The prevalence of childhood blindness in low income countries is estimated by the World Health Organization at 1.5 per 1,000 children. ${ }^{1}$ In sub-Saharan Africa, corneal pathologies account for $31 \%$ of cases. ${ }^{1}$ Their causes include vitamin A deficiency, ophthalmia neonatorum, and the use of traditional eye medicine (TEM). ${ }^{2}$

In Cameroon, the cornea has been reported as the leading site of abnormality in schools for the blind, ${ }^{3}$ although hospital-based studies on childhood blindness have reported other sites. ${ }^{4,5}$ This study aims to describe the different corneal diseases and to determine the prevalence of corneal blindness amongst children seen at a tertiary hospital.

\section{Material and methods}

This was a retrospective study (2002-2010) that was approved by the Yaoundé GynaecoObstetric and Paediatric Hospital's ethical committee. The records of children aged 0-15 years who presented with corneal pathologies were reviewed. The data collected included age, sex, past history, delay in presentation (duration between onset of symptoms and presentation), initial visual acuity, type of corneal lesion, and visual acuity at last follow-up. Cases with corneal involvement resulting from an intraocular
Correspondence: Viola A Dohvoma

Ophthalmology Unit, Yaoundé Gynaeco-Obstetric and Paediatric Hospital, PO Box 4362 Yaoundé, Cameroon

Tel +2379973 5506

Fax +237 22237429

Email andinv@gmail.com 
disease, such as glaucoma, were excluded. The World Health Organization's definition of blindness was used: "corrected visual acuity in the better eye of less than $1 / 20 .{ }^{\prime 1}$ Data analysis was performed using SPSS Statistics version 17.0 (IBM Corporation, Armonk, NY, USA) and Office Excel 2007 (Microsoft Corporation, Redmond, WA, USA).

\section{Results}

A total of 29,685 new patients were seen, including 7,922 children. Corneal pathologies were seen in 168 children, giving a prevalence of $2.1 \%$ (Table 1). There were 98 males and 70 females, representing $2.6 \%$ and $1.74 \%$, respectively, of the male and female children (Table 1). This difference was statistically significant when these proportions were compared using the chi-square test $(P=0.0086)$.

Ages ranged from 2 weeks to 15 years, with a mean ( \pm standard deviation) of $7.1 \pm 4.4$ years and a median of 7.0 years. Children aged $0-5$ years and $6-10$ years, were the most represented groups ( $n=65$ for each) (Figure 1).

Delay in presentation varied with the etiological category of the lesion. It was approximately 1 day for cases with chemical injury; 34 days for mechanical injury, with $25.7 \%$ ( $n=18 / 70$ ) examined within 24 hours following injury; 52 days for infections; and 1,827 days for dystrophies.

Predisposing factors included ocular trauma in 71 cases (43.3\%); ocular surface infection, including conjunctivitis and blepharoconjunctivitis, in 15 cases $(8.9 \%)$; the use of traditional eye medicine in eight cases $(4.8 \%)$; systemic disease in two cases, including Stevens-Johnson syndrome and xeroderma pigmentosum (1.2\%); family history of corneal dystrophy in two cases $(1.2 \%)$; and ocular herpes in one case $(0.6 \%)$.

Corneal pathology was unilateral in $86.3 \%$ of cases $(n=145)$ and bilateral in $13.7 \%(n=23)$. The most frequent anatomical lesions were scars of unknown origin $(16.1 \%)$ and superficial foreign bodies (14.3\%). The most frequent etiologies of corneal pathologies were trauma (81 cases [48.2\%]) and infection (47 cases [28.0\%]) (Figure 2). The diagnosis of corneal infection was clinical. Seven cases had a characteristic herpes simplex dendritic keratitis. Trauma

Table I Prevalence of corneal diseases in children

\begin{tabular}{|c|c|c|c|c|c|c|c|}
\hline \multirow[t]{2}{*}{ Cases } & \multicolumn{2}{|l|}{ Total } & \multicolumn{2}{|c|}{ Males (M) } & \multicolumn{2}{|c|}{ Females (F) } & \multirow[t]{2}{*}{ M:F } \\
\hline & $\mathbf{n}$ & $\%$ & $\mathbf{n}$ & $\%$ & $\mathbf{n}$ & $\%$ & \\
\hline $\begin{array}{l}\text { Children seen } \\
\text { at consultation }\end{array}$ & 7,922 & 26.7 & 3,827 & 48.3 & 4,095 & 51.7 & 0.9 \\
\hline $\begin{array}{l}\text { Children with } \\
\text { corneal pathology }\end{array}$ & 168 & 2.1 & 98 & 58.3 & 70 & 41.7 & $\mathrm{I} .4$ \\
\hline
\end{tabular}

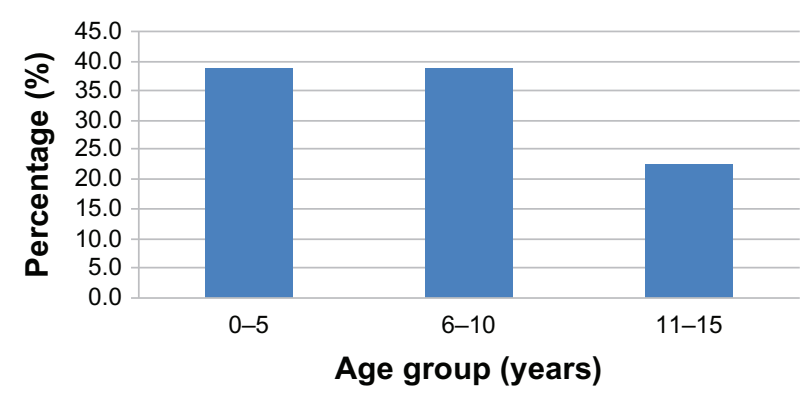

Figure I Distribution according to age group.

was the most frequent etiology in all age groups, with the highest prevalence of 58.5\% $(n=38)$ occurring amongst those aged $6-10$ years. Infection was most common amongst those aged $0-5$ years.

Initial visual acuity was not available in 59 cases (35.1\%). Out of the 109 cases, 51\% registered an initial visual acuity of $\geq 0.3$ (Table 2 ). Follow-up data was available only in 34 cases $(20.2 \%)$. The duration of follow-up ranged from 1-52 weeks. Visual acuity at last follow-up was available in 24 cases (while there was inability to cooperate in ten cases). Visual impairment and blindness were recorded in 12 cases (50\%), with one case being bilateral (Table 2). Seven of the 12 cases $(58.3 \%)$ resulted from trauma.

\section{Discussion}

The prevalence of corneal pathology among the children in this study was $2.1 \%$. Corneal pathologies are usually not amongst the most prevalent ophthalmic pathologies in children. Refractive errors, conjunctivitis, trauma, eyelid, and orbital pathologies are usually the most prevalent. ${ }^{6-9}$

Srinivas reported a prevalence of $26.3 \%$ amongst 4,022 Indian children aged 0-16 years. ${ }^{10}$ Onabolu et al reported a prevalence of $42 \%$ amongst 169 children aged $0-16$ years in The Gambia. ${ }^{11}$ The difference in prevalence of corneal pathologies in this study, compared to the others, could be due to differences in the relative frequencies of specific entities.

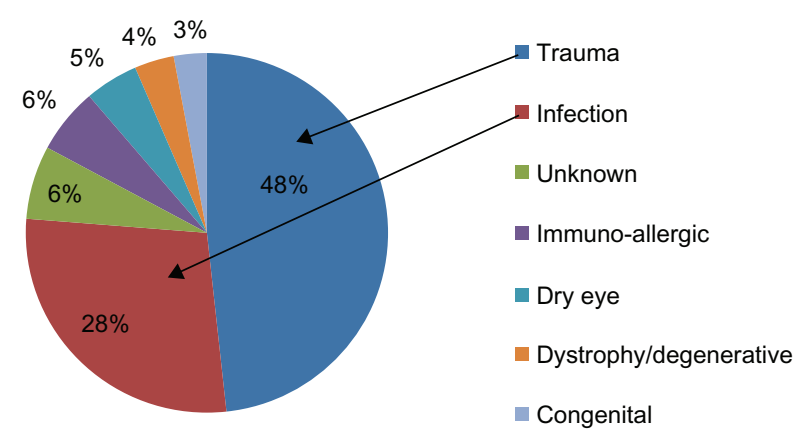

Figure 2 Etiological categorization of lesions. 
Table 2 Visual acuity at presentation and at last follow-up

\begin{tabular}{llllll}
\hline Visual acuity & \multicolumn{2}{l}{ First visit } & & \multicolumn{2}{c}{ Last follow-up } \\
\cline { 2 - 3 } & $\mathbf{n}$ & & & $\mathbf{n}$ & $\%$ \\
\hline$\geq 0.3$ & 56 & $5 \mathrm{I}$ & & 12 & 50 \\
$<0.3-1 / 20$ & 23 & 21 & 3 & 12 \\
$<1 / 20$ & 30 & 28 & & 38 \\
Total & 109 & 100 & & 24 & 100 \\
\hline
\end{tabular}

In The Gambia, vernal keratoconjunctivitis was reported in $22.5 \%$ of cases, as compared to $6 \%$ in this study. In the study from India, nutritional involvement represented $35.5 \%$ of the cases. No case of nutritional involvement was recorded in this study. This is due to the strategies put in place to combat vitamin A deficiency.

A significantly greater proportion of male than female children were affected by corneal pathologies. Srinivas reported a similar finding. ${ }^{10}$ This can be explained by the fact that trauma is the leading cause of corneal pathologies in children; boys are usually more involved in outdoor play than girls, and indulge in more aggressive play, which predisposes them to injury.

Identifiable risk factors were detected in $58.9 \%$ of cases, with ocular trauma being the most predominant. Besides direct traumatic involvement, trauma has been identified as a risk factor for microbial keratitis. ${ }^{12-14}$ Contact lens wear was the most important risk factor for microbial keratitis in Taiwanese children. ${ }^{15}$ The use of contact lenses is not common in our setting.

Late presentation of corneal pathologies was common. The mean time for presentation following mechanical injury was 34.3 days; $25.7 \%$ of cases were seen within 24 hours. In a study on ocular trauma in children in Douala, ${ }^{16} 55.5 \%$ of the children were seen within the first 24 hours. In a study from Ibadan, ${ }^{17}$ Nigeria, $23.4 \%$ were seen within the first 24 hours. Accessibility of hospitals, the cost of medical care, and the use of self-medication and TEM could explain the delay in presentation. Late presentation and the use of TEM can lead to poor outcomes. This study did not specifically seek to determine the types of TEM used. However, it was noted that, compared to urban dwellers, rural dwellers used TEM more frequently. The use of TEM depends on customs and beliefs. TEM mainly uses plant extracts (Citrus aurantifolia, Allium cepa) and human breast milk. In a study on the use of TEM by corneal ulcer patients in South India, Prajna et al reported the use of TEM in $47.7 \%$ of cases. ${ }^{18}$

The most frequent etiology was trauma ( $48.2 \%$ of cases). Onabolu et al also reported trauma as the most frequent etiology (32.4\%). ${ }^{11}$ Srinivas, however, reported nutritional involvement as the leading etiology, with trauma ranking fourth. Thirty-six (48.7\%) trauma cases were in children aged 6-10 years. Al-Bdour and Azab also reported a preponderance of injury in this age group. ${ }^{19}$ These are children of primary school age, who are physically more active. The lowest proportion of infective keratitis was from the 6-10 years age group (21.3\%), and the highest $(48.9 \%)$ from the $0-5$ years age group. The age distribution of patients with childhood microbial keratitis from southern India shows a similar trend, with $18.9 \%$ from the $6-10$ years age group. ${ }^{14}$ In our setting, the diagnosis of infective keratitis is usually made on a clinical basis, given that most cases use eye drops containing antibiotics before presentation.

Considering visual acuity at last follow-up, $50 \%$ cases suffered visual impairment and blindness. Onabolu et al reported that $45 \%$ of children with corneal diseases suffered blindness from trauma and from congenital diseases. ${ }^{11}$

Congenital diseases involving the cornea were uncommon $(3 \%)$. No case was reported by Srinivas in India, ${ }^{10}$ while Onabolu et al reported a prevalence of $16.9 \%$ in cases from The Gambia. ${ }^{11}$ The most frequent congenital eye anomalies are cataract and glaucoma. ${ }^{20,21}$

This study is limited by the high number of patients lost to follow-up, and the lack of microbiology reports for cases with suspected microbial keratitis.

\section{Conclusion}

Although the prevalence is low, corneal pathology in children leads to poor visual outcomes. Major causes in our setting are avoidable. Thus, parents, childhood health care givers, teachers, and children should be educated on the prevention of ocular injury.

\section{Disclosure}

The authors report no conflicts of interest in this work.

\section{References}

1. Gilbert C, FosterA. Childhood blindness in the context of VISION 2020 - the right to sight. Bull World Health Organ. 2001;79(3):227-232.

2. Gilbert C, Foster A. Blindness in children: control priorities and research opportunities. Br J Ophthalmol. 2001;85:1025-1027.

3. Noche CD, Bella AL. Fréquence et causes de cécité et de déficiences visuelles dans des écoles de malvoyants à Yaoundé (Cameroun). [Frequency and causes of blindness and visual impairment in schools for the blind in Yaoundé, Cameroon]. Santé. 2010;20(3):133-138. French.

4. Bella LA, Eballe AO, Kouam JM. Cécité et malvoyance bilatérales de l'enfant de 0 à 5 ans à 1'hôpital gynéco-obstétrique et pédiatrique de Yaoundé. [Bilateral blindness and visual impairment in children aged 0-5 years in the women's and children's hospital of Yaoundé]. Santé 2010;20(1):35-39. French.

5. Eballe AO, Epée E, Koki G, Bella L, Mvogo CE. Unilateral childhood blindness: a hospital-based study in Yaoundé, Cameroon. Clin Ophthalmol. 2009;3:461-464. 
6. Eballe AO, Bella LA, Owono D, Mbome S, Mvogo CE. La pathologie oculaire de l'enfant âgé de 6 à 15 ans: étude hospitaliére à Yaoundé. [Eye disease in children aged 6 to 15 years: a hospital-based study in Yaoundé]. Santé. 2009;19(2):61-66. French.

7. Onakpoya $\mathrm{OH}$, Adeoye AO. Childhood eye diseases in southwestern Nigeria: a tertiary hospital study. Clinics (Sao Paulo). 2009;64(10): 947-952.

8. Ajaiyeoba A. Childhood eye diseases in Ibadan. Afr J Med Med Sci. 1994;23(3):227-231.

9. Onyekonwu GC. Pattern of eye diseases In Nigerian children seen at Ebonyi State University Teaching Hospital (EBSUTH), Abakaliki, Nigeria. Ebonyi Med J. 2008;7:4-7.

10. Srinivas C. Corneal diseases as leading causes of blindness in Indian children. In: Shimuzi K, editor. XIII Congress of the Asia-Pacific Academy of Ophthalmology. Kyoto: ExcerptaMedica; 1991:1-4.

11. Onabolu ROO, Iwuora NA, Ceesay W. Corneal diseases in children in The Gambia. Niger J Ophthalmol. 2009;17(1).

12. Singh G, Palanisamy M, Madhavan B, et al. Multivariate analysis of childhood microbial keratitis in South India. Ann Acad Med Singapore. 2006;35(3):185-189.

13. Ashaye A, Aimola A. Keratitis in children as seen in a tertiary hospital in Africa. J Natl Med Assoc. 2008;100(4):386-390.
14. Kunimoto DY, Sharma S, Reddy MK, et al. Microbial keratitis in children. Ophthalmology. 1998;105(2):252-257.

15. Hsiao $\mathrm{CH}$, Yeung L, Ma DH, et al. Pediatric microbial keratitis in Taiwanese children: a review of hospital cases. Arch Ophthalmol. 2007;125(5):603-609.

16. Bella-Hiag AL, Ebana Mvogo C. Traumatologie oculo-orbitaire infantile à l'hôpital Laquintinie de Douala (Cameroun). [Ocular traumatism in children at Laquintinie Hospital, Douala (Cameroon)]. Santé. 2000;10(3):173-176. French.

17. Ashaye AO. Eye injuries in children and adolescents: a report of 205 cases. J Natl Med Assoc. 2009;101(1):51-56.

18. Prajna VN, Pillai MR, Manimegalai TK, Srinivasan M. Use of Traditional Eye Medicines by corneal ulcer patients presenting to a hospital in South India. Indian J Ophthalmol. 1999;47(1):15-18.

19. Al-Bdour MD, Azab MA. Childhood eye injuries in North Jordan. Int Ophthalmol. 1998;22(5):269-273.

20. Lawan A. Congenital eye and adnexial anomalies in Kano, a five year review. Niger J Med. 2008;17(1):37-39.

21. Chuka-Okosa CM, Magulike NO, Onyekonwu GC. Congenital eye anomalies in Enugu, South-Eastern Nigeria. West Afr J Med. 2005; 24(2):112-114.
Clinical Ophthalmology

\section{Publish your work in this journal}

Clinical Ophthalmology is an international, peer-reviewed journal covering all subspecialties within ophthalmology. Key topics include: Optometry; Visual science; Pharmacology and drug therapy in eye diseases; Basic Sciences; Primary and Secondary eye care; Patient Safety and Quality of Care Improvements. This journal is indexed on Submit your manuscript here: http://www.dovepress.com/clinical-ophthalmology-journal

\section{Dovepress}

PubMed Central and CAS, and is the official journal of The Society of Clinical Ophthalmology (SCO). The manuscript management system is completely online and includes a very quick and fair peer-review system, which is all easy to use. Visit http://www.dovepress.com/ testimonials.php to read real quotes from published authors. 